\title{
La recuperación del estandarte real del Ayuntamiento de Sanlúcar de Barrameda
}

En el año 2015 el Instituto Andaluz del Patrimonio Histórico recibe el encargo de recuperar el estandarte real de Sanlúcar de Barrameda, propiedad del Ayuntamiento de la ciudad. Este pendón real, cuyo origen se remonta a 1665, y que se había utilizado en la ceremonia de proclamación de al menos cinco monarcas españoles, presentaba un estado de deterioro bastante importante. Para el IAPH el reto de esta actuación era, además de recuperar su unidad estética, consolidar la obra respetando la visibilidad de las dos caras, tal como fue creada en origen.

Carmen Ángel Gómez | Centro de Intervención del IAPH

URL <http://www.iaph.es/revistaph/index.php/revistaph/issue/view/4358>

El estandarte real de Sanlúcar de Barrameda está inscrita en el Catálogo General del Patrimonio Histórico de Andalucía como bien incluido en el Inventario General de Bienes Muebles del Patrimonio Histórico Español, por lo que, para su recuperación, se exigía la realización de un proyecto de conservación con arreglo a lo dispuesto en el art. 21.1 de la Ley 14/2007, de 26 de noviembre, de Patrimonio Histórico de Andalucía. Dicho proyecto, elaborado por el IAPH, contempló la planificación de todas las actuaciones científico-técnicas necesarias para el conocimiento del bien y su posterior restauración, según la metodología y los criterios que deben regir una obra textil de estas características.

El origen del estandarte real parece remontarse al año 1665, relacionado con la proclamación de Carlos II como rey de España. Según la documentación estudiada en el archivo del Ayuntamiento de Sanlúcar de Barrameda, existen datos relacionados con la organización de esta ceremonia y el encargo para realizar un pendón con las armas del monarca, con los escudos de la casa de España y de Austria. Además de otras reseñas, también se acuerda que estuviese siempre guardado en el archivo del Ayuntamiento. Igualmente, se tiene constancia documental sobre la participación de este pendón real en la proclamación de cuatro monarcas españoles más.

\section{Fase cognoscitiva}

En una primera fase, con la implicación de especialistas en diversos campos para obtener un conocimiento glo-

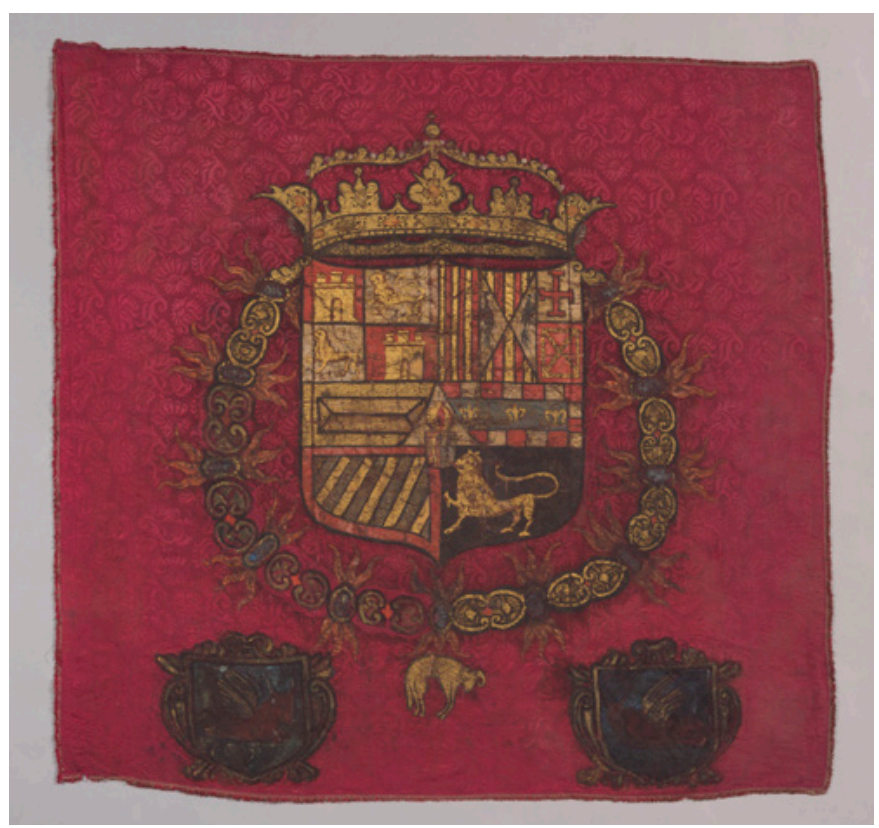

Anverso del estandarte real de la ciudad de Sanlúcar de Barrameda. Obra finalizada | fotos Fondo Gráfico IAPH (José Manuel Santos Madrid)

bal, se recabó toda aquella información relacionada con los antecedentes históricos, las características materiales, la evaluación de los factores de deterioro, las circunstancias de riesgos y las patologías presentes, con el apoyo de medios técnicos y científicos, para configurar una propuesta de tratamiento adecuada a este tipo de bien y a su estado de conservación. Debido a las características formales y la complejidad de conservación de este estandarte, se realizó una búsqueda bibliográfica 

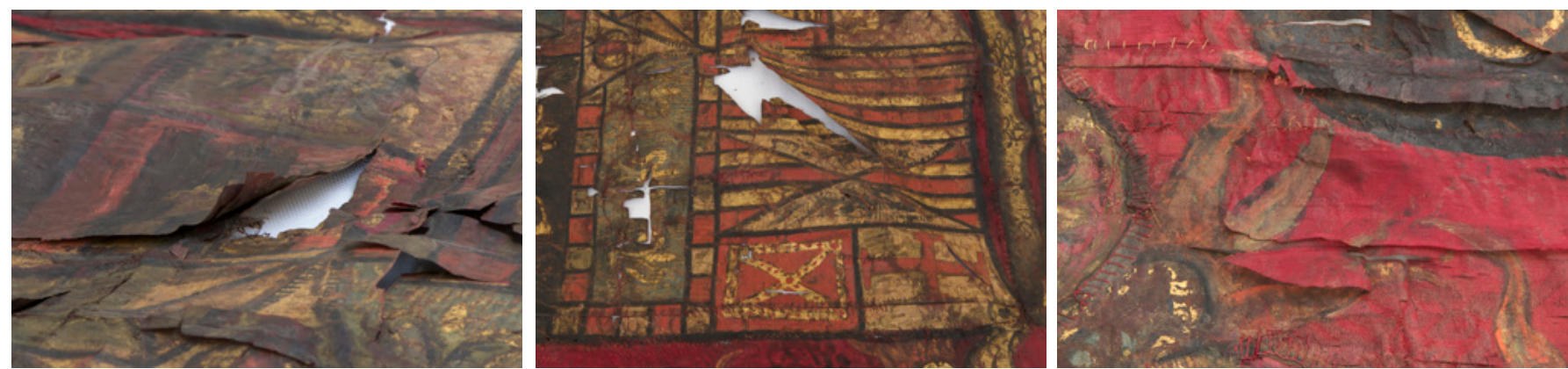

De izquierda a derecha: superposición de parches; eliminación de parches y deformaciones; eliminación de intervenciones

sobre intervenciones en conservación y restauración de obras textiles con características similares, y en particular sobre la consolidación de obras creadas, en origen, para ser vistas por ambas caras. Se completó esta información con los resultados de los análisis de identificación de las fibras por microscopia óptica, examen de los pigmentos de la pintura por fluorecencia de rayos $X$ y estudios técnicos para determinar el tipo de ligamento del tejido y la forma de confección del estandarte.

Esta obra está realizada para ser vista por las dos caras, sobre un tejido de damasco carmesí está pintado el escudo de Carlos II en el centro y otros dos más pequeños en las esquinas de la parte inferior que representan a la ciudad de Sanlúcar de Barrameda. El escudo real está pintado directamente sobre el damasco, con una finísima capa de preparación, una capa de bol sobre ésta y cubierta con láminas de pan de oro, sobre el que se pintan los cuarteles del escudo. Los escudos de la ciudad de Sanlúcar también están pintados directamente sobre el tejido de damasco, aunque con un diseño diferente al cuerpo del estandarte real.

El estado de conservación de la obra textil era muy deficiente sobre todo en las zonas pintadas y alrededores, donde se concentraban la mayoría de las roturas y pérdidas, debidas a la falta de flexibilidad y resistencia de las fibras, evidenciando la necesidad de consolidación de la pieza textil para permitir su manipulación. El conjunto presentaba además suciedad, deformaciones y manchas, debidas tanto a las características técnica de ejecución, como al sistema expositivo, la ausencia de control ambiental y las numerosas intervenciones realizadas en el siglo XIX, detectadas en el análisis por fluo- rescencia de rayos $X$, identificando el uso de pigmentos como blanco de zinc o verde cromo, que se descubrieron en el siglo XIX, y albayalde, que se dejó de usar a comienzos del siglo XX debido a su toxicidad.

Las intervenciones más numerosas son los cosidos que unían las roturas del tejido y parches adheridos por una de las caras para mantener los elementos sueltos. La superposición de elementos indica que se han realizados varias actuaciones, aunque no se han podido determinar el momento de ejecución de cada una de ellas. El tipo de hilo empleado en muchas de las costuras realizadas determina que se cosieron al mismo tiempo que los escudos inferiores de la ciudad de Sanlúcar.

Teniendo presente la problemática que presentaba el estandarte, la propuesta se centró en devolverle la consistencia material al soporte, recuperar la unidad estética de la obra y frenar el grave deterioro y fragilidad producidos por el paso de los años, por su sistema de exhibición y por las numerosas intervenciones anteriores que, si bien en su momento ayudaron a su preservación, en la actualidad ejercían como un agente de degradación. El reto de esta intervención era consolidar esta obra respetando la visibilidad de las dos caras, como fue creada en origen.

\section{Fase operativa}

Tras realizar varias consultas sobre tratamientos de piezas textiles, se decidió llevar a cabo una consolidación con soporte semitransparente y adhesivo, por la cara considerada como el reverso de la obra. Aunque el empleo de adhesivos es un proceso invasivo y no del todo reversible, se descartó el sistema de costura 

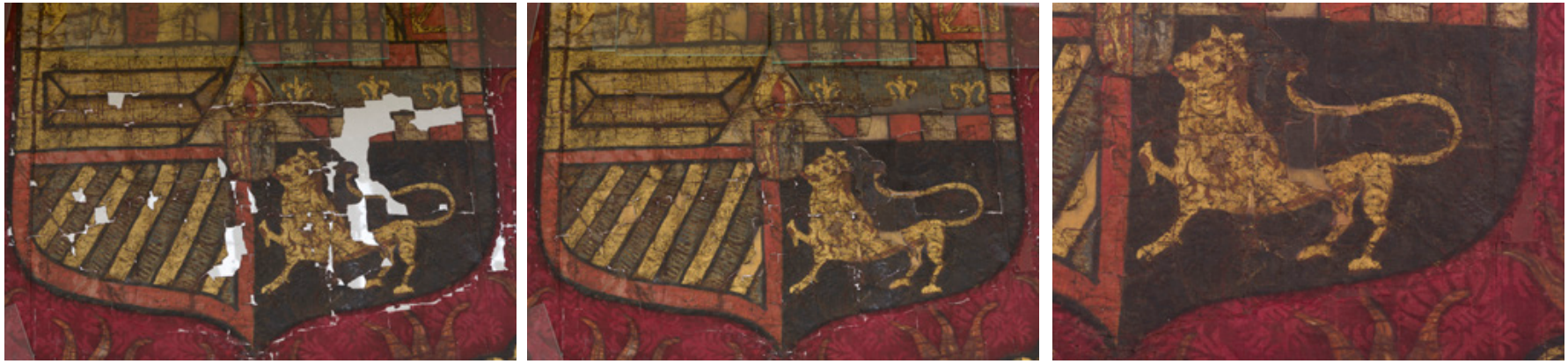

De izquierda a derecha: reintegración de lagunas; detalle tras la reintegración

por la facilidad de fragmentación de la zona pintada durante la manipulación del estandarte. En la elección del soporte de consolidación se optó por un tejido de organza (crepelina) de seda natural que se caracteriza por su transparencia. Este tejido supone una veladura al conjunto, pero permite cierta visibilidad del escudo de la cara del reverso, siendo aún más visible cuando el tejido es teñido.

Para la adhesión del soporte textil y tras las pruebas realizadas de reversibilidad y compatibilidad, se seleccionó un adhesivo de tipo celulósico, aplicado mediante humedad sin necesidad de calor (adhesivo de la familia de polímeros termoplásticos constituidos por poli(2-etil-2oxazolina), empleado como consolidante en capas pictóricas y en papel, conocido como Aquazol ${ }^{\circledR}$.

Con relación a la recuperación de la unidad estética de la obra, se llevó a cabo la reintegración de las lagunas, respetando en todo momento el original. Tras realizar varios ensayos con soportes de tejidos teñidos, sin resultados satisfactorios, se planteó la necesidad de otro sistema de reintegración. Finalmente, se estableció hacer pruebas con injertos de papel, que se podían ajustar al tamaño de cada laguna e insinuar el diseño de los cuarteles perdidos mediante la reproducción del dibujo. Debido a las características de partición del escudo y la posibilidad de comparar ambas caras, la continuidad del diseño era bastante fácil de reproducir.

El papel elegido es artesanal, formado por la mezcla de plantas naturales (cáñamo y algodón), con reserva alcalina y un gramaje de $55 \mathrm{~g} / \mathrm{m}^{2}$. El dibujo se realizó con témpera, por su capacidad de cobertura. Para facilitar el trabajo de integrar las dos caras se consideró utilizar dos fragmentos del mismo tamaño en cada laguna, unidos por el mismo adhesivo utilizado con la crepelina.

El primer paso en la intervención fue el desmontaje de los elementos constitutivos, asta y corbata, para poder eliminar las deformaciones producidas por la costura de la vaina y las numerosas intervenciones realizadas con anterioridad. Las deformaciones se trataron mediante la aplicación de humedad con vapor frío. Debido a la dificultad de manipulación, se realizó una cámara que se pudiese desmontar con facilidad y permitiese aplicar humedad de modo controlado a toda la obra. Para ello, se conectaron dos humidificadores de ultrasonido en esquinas opuestas. El proceso se realizó en varias fases, vigilando el tiempo de humectación, para evitar el exceso de humedad sobre la pintura.

En cuanto a las intervenciones realizadas con anterioridad, se eliminaron los zurcidos y parches que afectaban a la integridad física de la obra, manteniéndose aquellas actuaciones que se consideraron como parte de la historia material de la pieza (escudos de la ciudad de Sanlúcar y añadidos en el Toisón). La retirada de estas intervenciones dejó al descubierto un mayor número de pérdidas que no se veían al inicio, debido a que muchos de los zurcidos se habían realizado casando y montando los bordes para cerrarlos, así como también la existencia de fragmentos de los escudos que estaban ubicados incorrectamente.

Tras la alineación del tejido, se optó por una limpieza mecánica, que permitió eliminar la suciedad y reducir algunas manchas de pintura. El tratamiento consistió en 
la aspiración con una pequeña bomba de vacío, sobre el tejido y la pintura. Puntualmente, se trataron las manchas producidas por los repintes con solventes.

Previo a la consolidación, se ubicaron los fragmentos sueltos que se habían colocado incorrectamente durante las intervenciones anteriores, para determinar el límite de las lagunas a reintegrar. Para su correcta disposición, se utilizó una plantilla con el diseño del tejido de damasco que, a modo de guía, permitió la correcta distribución de los fragmentos dudosos. Las lagunas fueron calcadas en acetato, para usarse como plantilla de los injertos que se tenían que recortar y reintegrar en papel.

El soporte de consolidación fue teñido con Lanaset, tinte sintético para tejidos de seda que presenta una gran estabilidad. Para la obtención del color, se efectuaron varias pruebas de teñido mediante la mezcla de tres colores, hasta conseguir el ajuste definitivo. La crepelina teñida, con el tamaño justo para cubrir los escudos, se impregnó con el adhesivo mediante el uso de brocha y en una proporción del 5\% disuelto en agua desmineralizada. Tras secar, se activó mediante calor de espátula térmica. Las pequeñas roturas del tejido fueron integradas con hilos de seda entonados según el color del damasco y fijados mediante calor a la crepelina. En todo el proceso de adhesión se utilizó como aislante un mylar.

Para evitar riesgo de manipulación, se decidió proteger la cara del anverso con un tul de nailon entonado con el conjunto de la obra, con la mezcla de tres pigmentos de tinte Lanaset. La fijación de este tejido al pendón se realizó al límite del galón perimetral y se complementó con líneas de fijación, realizadas sobre el tejido de damasco que quedaba libre de la crepelina de consolidación.

\section{En conclusión}

Se puede decir que la restauración llevada a cabo logró frenar el deterioro que presentaba el estandarte real, estabilizándola, manteniendo su valor testimonial, simbólico, estético y de antigüedad, y permitiéndole perdurar en el tiempo, a la vez que ser exhibida.

Uno de los aspectos interesantes en la intervención del estandarte, fue la necesidad de recurrir a planteamientos metodológicos de otras especialidades de restauración para el desarrollo de los tratamientos más adecuados para el conjunto de esta obra textil.

La consolidación y reintegración fue todo un reto, por los inconvenientes que planteaba el empleo de calor y adhesivos sobre los tejidos, pero el método aplicado ha resultado el más adecuado para las alteraciones que presentaba la pieza, además de proporcionar una correcta lectura del escudo como elemento principal de la obra.

Los estudios realizados y la recuperación del estandarte real ha supuesto la puesta en valor de un pieza apenas conocida por los sanluqueños y que es parte de la historia de esta ciudad.

\section{BIBLIOGRAFÍA}

- MONTESIONS FERRANDIS, E. M.; VICENTE PALOMINO, S.; FUSTER LÓPEZ, L.; YUSÁ MARCO, D. J.; DOMÉNECH CARBÓ, M. T.; MECKLENBURG, M. F. (2008) Aproximación al estudio de adhesivos para la consolidación y refuerzo de tejidos Históricos: materiales y métodos. ARCHÉ, n. ${ }^{0} 3,2008$, pp. $143-146$

- La BANDERA de Santa Eulalia: un tratamiento de conservación integral (2014) [en línea] Unicum, n. ${ }^{\circ} 13,2014$ pp. 157-178 <https://www.raco.cat/index.php/UNICUM/article/ viewFile/283152/371034> [Consulta: 13/12/2018]

- RIVERA SÁNCHEZ, C.: CAMPOS ÁlVAREZ, F. (2010) Restauración de la bandera de la Jura de la Independencia. Conserva, n. ${ }^{\circ} 14,2010$, p. 37

- SANZ DOMínguEZ, E. (2015) Colecciones textiles en museos militares: Tipología y problemática de conservación y restauración. Tesis doctoral. Universidad Complutense de Madrid, 2015 